\title{
DESIGN AND MANUFACTURE OF A REPLICATING POSITIONER
}

\author{
Bharadwaj K R $\mathbf{1}^{1}$, Darshan BG ${ }^{2}$, Lingaraju.L ${ }^{3}$, Manjeet Kumar ${ }^{4}$, Srinivas $\mathbf{R}^{5}$ \\ ${ }^{1}$ Assistant Professor, Mechanical Engineering Department, T John Institute of Technology, Bangalore, Karnataka, \\ India \\ ${ }^{2}$ Assistant Professor, Mechanical Engineering Department, Don Basco Institute of Engineering, Bangalore, \\ Karnataka, India \\ ${ }^{3}$ Assistant Professor, Mechanical Engineering Department, T John Institute of Technology, Bangalore, Karnataka, \\ India \\ ${ }^{4}$ Bachelor of Engineering, Mechanical Engineering Department, T John Institute of Technology, Bangalore, \\ Karnataka, India \\ ${ }^{5}$ Assistant Professor, Mechanical Engineering Department, T John Institute of Technology, Bangalore, Karnataka, \\ India
}

\begin{abstract}
Generally, the positioning for various machining operation are carried out using jigs, fixtures, SPM's (special purpose machines), CNC machine etc, which consumes large amount of time and money. Due to intense competitions in the market there is a desperate need to deliver components with minimal time and cost. All the above constrain have passed the way for the development of a new technique called "REPLICATING POSITIONER" that makes use of a locating plunger when the plunger is moved to a location. This technique, if employed, reduces the time and cost to a considerable value thus making it economically viable.
\end{abstract}

The working of replicating positioner can be explained as follows:

Consider that a customer wants a rectangular plate with 9 holes on the surface. In current day practice, this need can be accomplished by using a jig boring machines or SPM's or other CNC machines. Use of these machines consumes lot of time and money. This can be minimized by using the replicating positioner which makes use of a locating plunger to replicate the position of the holes i.e. when given such kind of a plate with multiple holes and if the number of pieces required is more, then a model/template as per the given drawing is manufactured which acts as a reference for the rest of the pieces. This is done by fixing the model/template onto a plate at the bottom of the positioner and then a plunger is fixed to the slide using a bracket. The work is placed on top of the surface and is centralized with the drilling machine spindle. After this the spring loaded plunger is inserted onto the first hole of the 9 holes and the whole setup is clamped and the drilling of that hole is carried out. To drill the next hole, the plunger is pulled up and moved to the second hole so the same distance is travelled by the work with respect to the machine spindle and is thus the second one is drilled. Similarly by moving the plunger to all the 9 holes and by clamping, multiple holes can be drilled in a short span of time without any jigs which is more economical than any other techniques.

Keywords: Replicating Positioner, jigs and Fixtures, Plunger, Template.

\section{INTRODUCTION}

A replicating positioner is a new technique used to eliminate the consumption of large amount of time and money which is involved in traditional/conventional positioning methods followed for various machining operations.

Conventional methods include use of jigs, fixtures, special purpose machines ( SPM's), CNC machines etc...Thus a replicating positioner helps in minimizing the use of the above expensive technologies and promises to be handy in eliminating the use of jigs so that appreciable amount of time and money is saved and thus can be economically viable.

\subsection{Advantages of Replicating Positioner}

- Saves time in jig and fixture manufacturing

- Economically beneficial compared to other techniques

- Saves jig cost

- Eliminates the use of bushes

- Skilled workers are not required

- Ease in maintenance

- Accuracy is high in its class

\subsection{Applications of Replicating Positioner}

- Printed Circuit Boards ( PCB's )

- Flanges

- Automobile components

- Large volume production 


\section{INTRODUCTION TO MACHINE DESIGN}

Machine design is the art of developing new ideas for the construction of machines and expressing those ideas in the form of plans and drawings.

\subsection{Design Procedure}

The procedure for designing a machine involves the following steps:

- Statement of problem

- Analysis of problem

- Selection of materials and stresses

- Preparation of preliminary design

- Division of design

- Making of final drawings

\subsection{Unigraphics NX-6/7.5}

Unigraphics NX-6/7.5 is a high end design software package which is used to create models as per the requirement. The models created using this package will be shown in the subsequent chapters.

\subsubsection{Base}

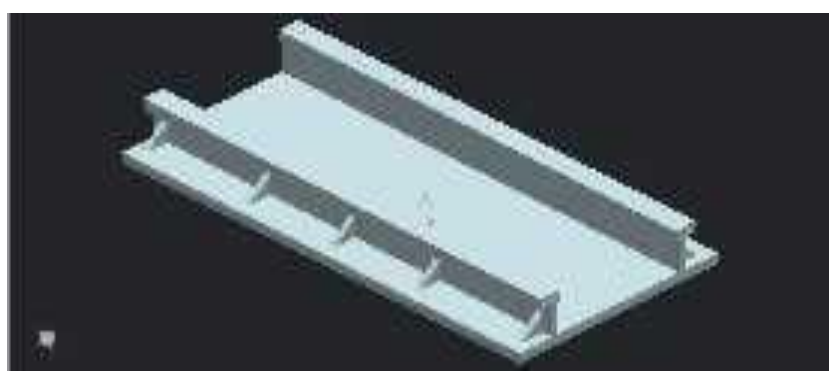

The base of the replicating positioner is modeled as shown above which acts as a foundation to the entire setup. The material used in the manufacture of the above part is cast iron.

Table 1.1: Specifications of Base

\begin{tabular}{|l|l|}
\hline Length & $1000 \mathrm{~mm}$ \\
\hline Width & $500 \mathrm{~mm}$ \\
\hline Wedge Thickness & $4 \mathrm{~mm}$ \\
\hline Base Height & $135 \mathrm{~mm}$ \\
\hline Base Thickness & $30 \mathrm{~m}$ \\
\hline
\end{tabular}

\subsubsection{Slides}

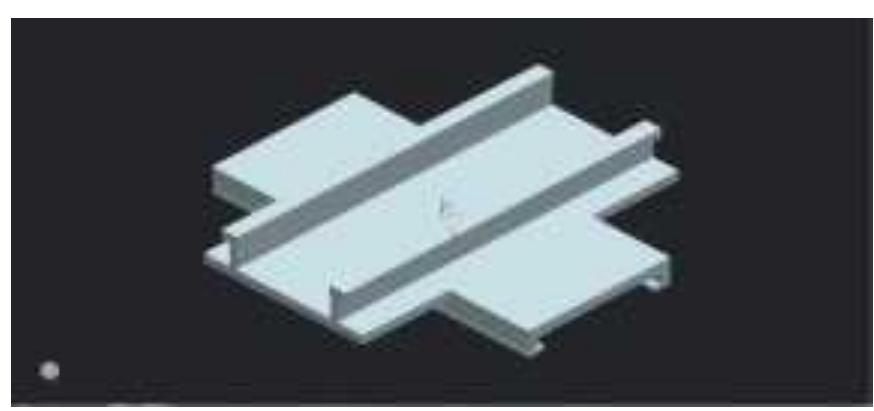

The slides are used to accommodate the work piece and the $\mathrm{X}$ - Y movements can be got to adjust the position of the machining point while the spindle position is unchanged.

Table 1.2: Specifications of slides

\begin{tabular}{|l|l|}
\hline Top Slide length & $1000 \mathrm{~mm}$ \\
\hline Top Slide Width & $500 \mathrm{~mm}$ \\
\hline Bottom Slide Length & $1000 \mathrm{~mm}$ \\
\hline Bottom Slide Width & $500 \mathrm{~mm}$ \\
\hline Guide Plate Width and Length & $30 \mathrm{~mm} \& 1000 \mathrm{~mm}$ \\
\hline
\end{tabular}

\subsubsection{Bracket}

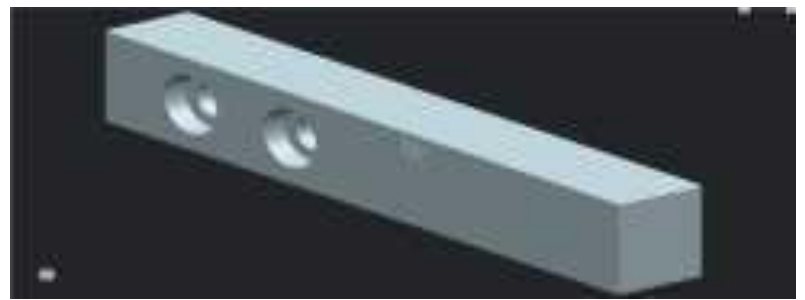

The bracket is used for fixing the spring loaded plunger onto the replicating positioner. The bracket is counterbored and fastened with allen screws and the plunger is welded to the end of the plunger.

Table 1.3: Specifications of Bracket

\begin{tabular}{|l|l|}
\hline Length & $750 \mathrm{~mm}$ \\
\hline Width & $30 \mathrm{~mm}$ \\
\hline Hole Diameter & $8 \mathrm{~mm}$ \\
\hline Counterbore Diameter & $15 \mathrm{~mm}$ \\
\hline Counterbore Depth & $5 \mathrm{~mm}$ \\
\hline Thickness of bracket & $30 \mathrm{~mm}$ \\
\hline
\end{tabular}

\subsubsection{Plunger}

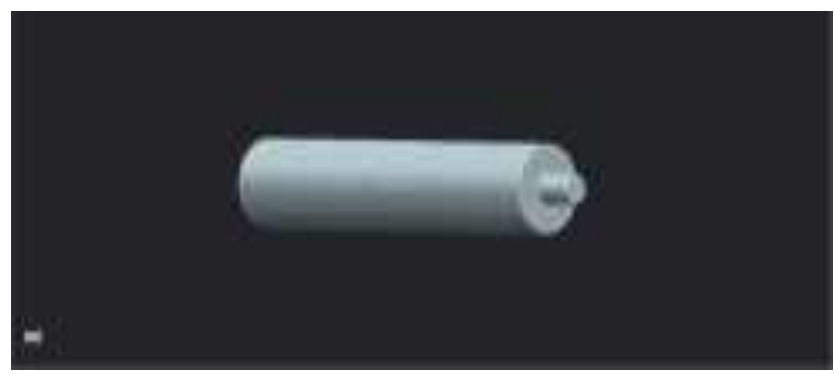

The plunger plays an important role in the working of the replicating positioner. The plunger is spring loaded and is provided with a knurled head for gripping purpose. The plunger is welded onto the bracket. The function of plunger is to locate the holes in the template and replicate the same onto the workpiece. 
Table 1.4: Specifications of Plunger

\begin{tabular}{|l|l|}
\hline Diameter of Body & $50 \mathrm{~mm}$ \\
\hline Length of Body & $100 \mathrm{~mm}$ \\
\hline Plunger Diameter & $10 \mathrm{~mm}$ \\
\hline Plunger length & $20 \mathrm{~mm}$ \\
\hline Spring Type & Helical \\
\hline
\end{tabular}

\subsubsection{Template}

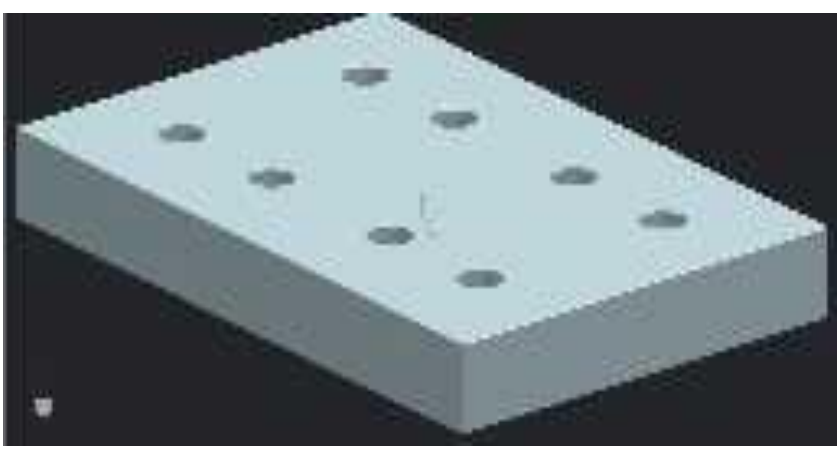

The template is face and end milled to the desired accuracy and dimension. Holes are then drilled on it with a high level of accuracy so that the parts manufactured keeping it as a reference will retain the same level of sophistication.

Table 1.5: Specifications of Template

\begin{tabular}{|l|l|}
\hline Length & $150 \mathrm{~mm}$ \\
\hline Width & $100 \mathrm{~mm}$ \\
\hline Thickness & $20 \mathrm{~mm}$ \\
\hline Diameter of holes & $10 \mathrm{~mm}$ \\
\hline Longitudinal Pitch & $20 \mathrm{~mm}$ \\
\hline Transverse Pitch & $25 \mathrm{~mm}$ \\
\hline
\end{tabular}

\subsubsection{Assembly}

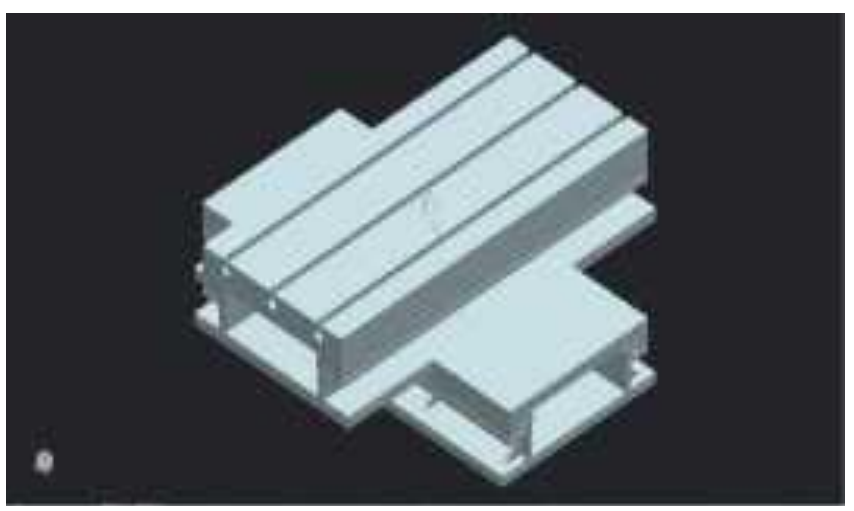

The final assembly of the replicating positioner is as shown above. All the parts manufactured through various processes are assembled to form the final assembly.
Table 1.6: Specifications of Assembly

\begin{tabular}{|l|l|}
\hline Length of the Base and slide & $1000 \mathrm{~mm}$ \\
\hline Width of Base and slide & $500 \mathrm{~mm}$ \\
\hline Total height of the assembly & $500 \mathrm{~mm}$ \\
\hline Bracket Length & $750 \mathrm{~mm}$ \\
\hline Template Length and Width & $150 \mathrm{~mm}$ and $100 \mathrm{~mm}$ \\
\hline
\end{tabular}

\subsubsection{Antifriction Balls}

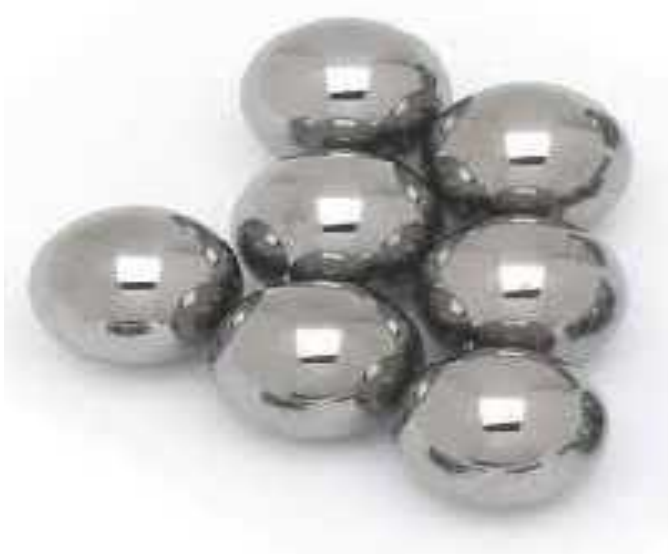

The anti-friction balls are used in the guides for frictionless movement of the guides/slides.

Table 1.7: Specifications of Anti-Friction Balls

\begin{tabular}{|c|c|}
\hline Ball Diameter & $4 \mathrm{~mm}$ \\
\hline Pitch on Location & $20 \mathrm{~mm}$ \\
\hline Material & Stainless Steel \\
\hline
\end{tabular}

\subsubsection{Sheet Metal Guard}

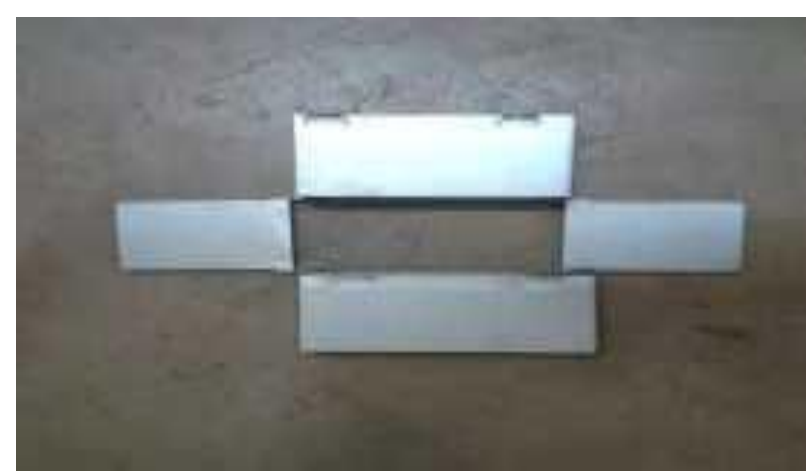

The sheetmetal guard as shown above is used to prevent the intervention of foreign particles in the movement of the slides which otherwise may result in restricted movement of the guides.

Table 1.8: Specifications of Sheetmetal Guard

\begin{tabular}{|c|c|}
\hline Length of Guard & $80 \mathrm{~mm}$ \\
\hline Width of Guard & $40 \mathrm{~mm}$ \\
\hline Material & Mild Steel (Cold Rolled) \\
\hline
\end{tabular}




\subsubsection{Locking Studd with Knob:}

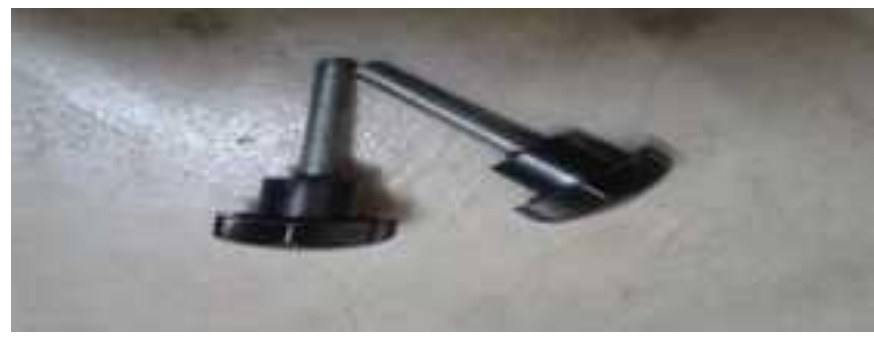

Its purpose is to arrest the movement of the guides in both $\mathrm{X}$ and the $\mathrm{Y}$ directions. The studd is made up of steel and the knob is made up of bakelite and this fixed onto the guide perpendicular to its axial movement.

Table 1.9: Specifications of Locking Studd and Knob

\begin{tabular}{|l|l|}
\hline Length of knob & $75 \mathrm{~mm}$ \\
\hline Diameter & $8 \mathrm{~mm}$ \\
\hline Thread Pitch & $1.5 \mathrm{~mm}$ \\
\hline Material of Handle & Bakelite \\
\hline
\end{tabular}

\section{MANUFACTURING PROCESS}

\subsection{Casting of Base and Slides}

Casting is a manufacturing process which involves pouring molten metal (ferrous and non ferrous) into a mould cavity whose shape resembles the shape of the desired product and allowing the molten metal to solidify it.

The casting of base and slides is done through expendable mould (i.e. the mould prepared from sand plaster or similar materials is temporary and is destroyed in order to remove the solidified part). In other words a new mould is prepared for each casting.

\subsection{Machining of the Base and Slides}

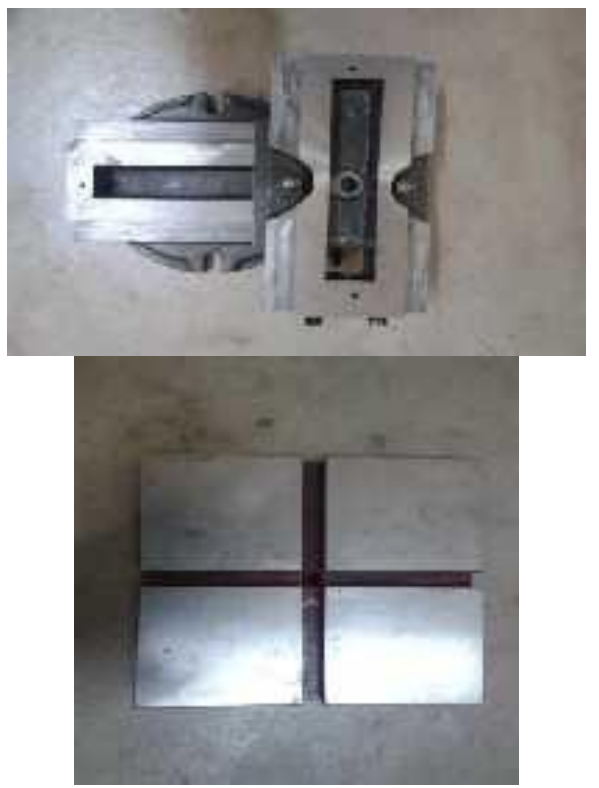

Fig 1.9: Base and Slide
Machinability: It is the characteristic of work material expressing an ease of machining. Most machinable metals permit removal of material with a satisfactory finish at low cost i.e, most machinable metals permit fastest removal of largest amount of material per grind of tool with satisfactory finish.

Operational characteristics of a cutting tool are generally described by its machinability.

\section{Criteria for Machinability:}

- Tool life

- Machinability ratings ( based on cutting speed )

- Cutting forces

- Surface finish

- Tool rigidity

The machining of base and slides are carried out after the casting stage, where there is an allowance given on the cast part for machining. Furthermore, the various finishing operations is carried out to meet the required dimension and is as shown in the above figure

\subsection{Jib to Adjust Clearance}

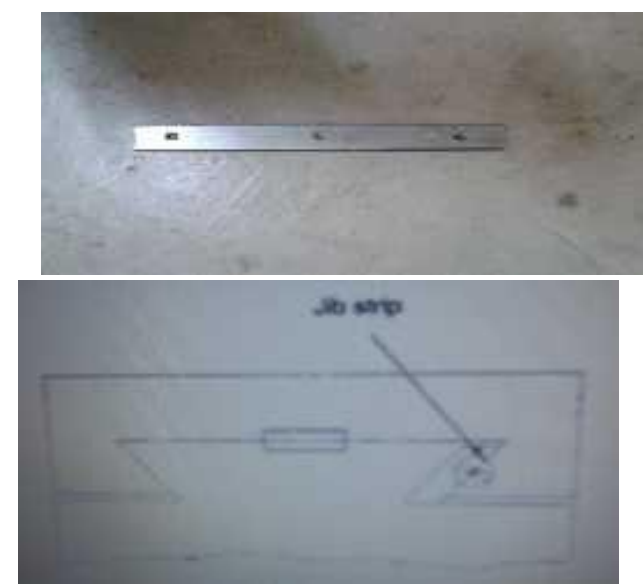

Fig 1.10: Jibs

Jibs are used to ensure accurate fitting of the slide to both the flat and dovetail guideways. The jibs are tapered and can be adjusted to reduce excessive clearance caused by wear.

\subsection{Grinding and Scraping the Dovetail for}

Accuracy

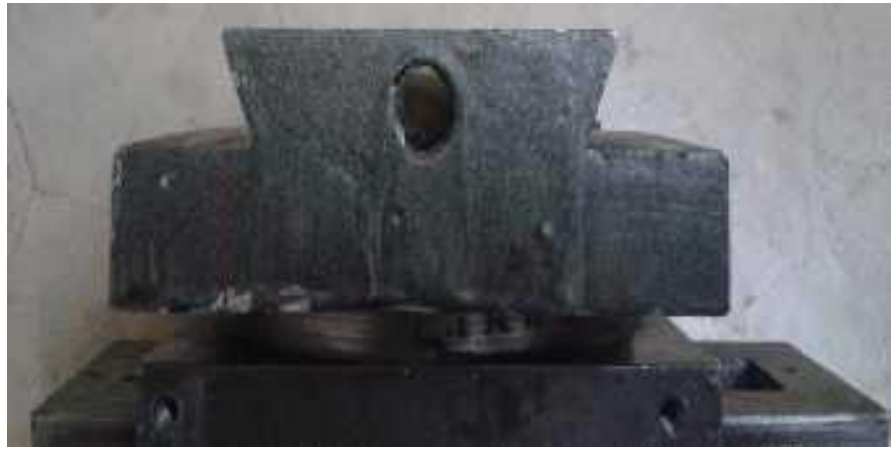

Fig 1.11: Dovetail 
A dovetail is a bearing surface, just like a plain bearing ..

Dovetail guides would be made of iron because of its good ability to capture oil film. They would be used on very big mill, built from scratch. If dovetail surface is not completely free of traces of rotating cutter, there is a possibility for a guide to get blocked, or for friction to increase, or small morsels could break away from sliding surface and consequently destroy it.

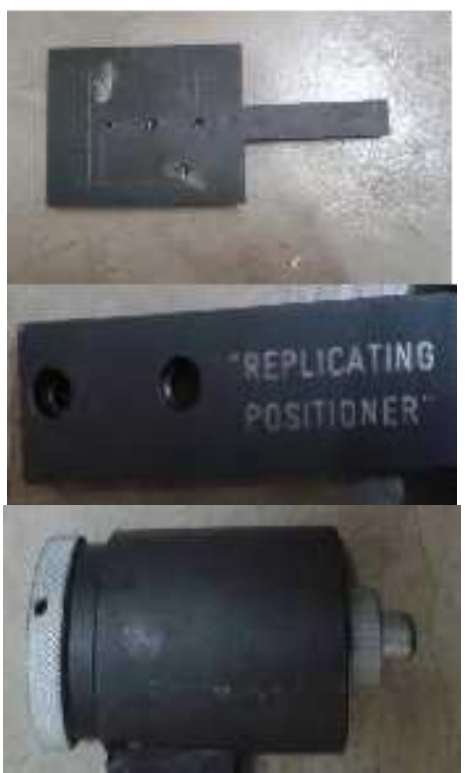

Fig 1.12: Fixing plate, Bracket, Plunger

The manufacturing process involved in manufacture of each part is as shown below:

\section{- Fixing plate:}

a. The mild steel raw material is taken and is then face and side milled to the suited dimension.

b. Suitable drill is taken and holes are drilled at certain positions at which the plates are fastened to the machine base.

c. Counterboring is done the drilled hole to accommodate the allen screw head.

\section{- Bracket:}

a. The mild steel raw material is taken and is then face and side milled to the suited dimension.

b. Suitable drill is taken and holes are drilled at certain positions at which the bracket is fastened to the guideways.

c. Counterboring of those holes are done to accommodate the allen screw head.

\section{- Plunger:}

a. The EN8 carbon steel raw material in the form of a cylinder is taken and turned down to the required dimension

b. Internal threading is done to a certain depth to accommodate the spring loaded plunger.

c. The turned plunger along with the handle is placed inside the plunger body and screwed.

\subsection{Rust Proofing}

\section{Electroplating:}

Electroplating is the application of electrolytic cells in which a thin layer of metal is deposited onto an electrically conductive surface. Here's a closer look at what electrochemistry is, how it works, and what metals and anodes are used. There are several reasons why you might want to coat a conductive surface with a metal. Silver plating and gold plating of jewelry or enhances corrosion resistance after painting and reduces sludge generation. The developed process has already been put to practical use for surface preparation before cation electrodeposition painting of automotive parts.

\subsection{Sheetmetal Fabrication of the Guard}

The fabrication of the sheetmetal guard goes through the following stages:

a. Marking the dimensions on the sheetmetal using a scribe.

b. Cutting it by the gas cutting machine into several known dimensioned pieces

c. Bending and forging the guards.

d. Welding several pieces using $\mathrm{He}-\mathrm{Ne}$ gas welding e. Grinding the extra weld materials.

f. Electroplating the sheetmetal guard.

The whole setup of the sheetmetal guard is as shown below:

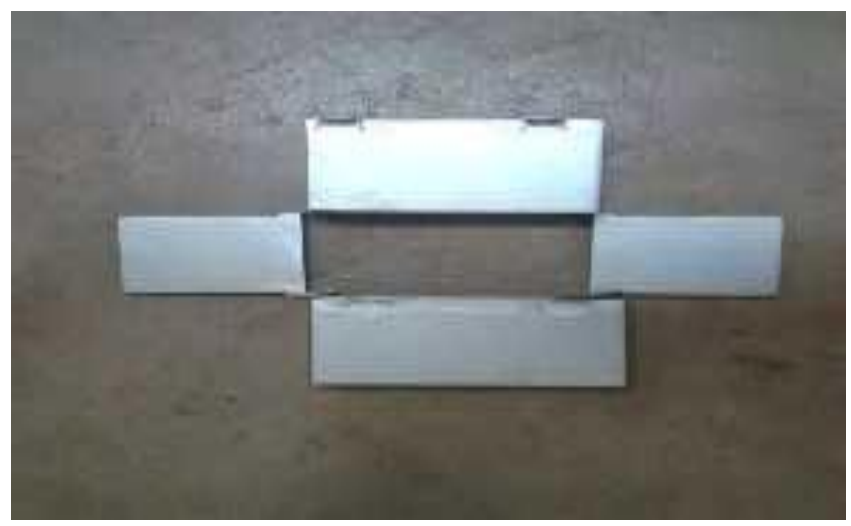

Fig 1.13: Sheetmetal Guard

\subsection{Sample Template Manufacturing}

The template plays an important role in deciding the accuracy of machining because if there is any error in the manufacture of this template, the same will be replicated onto the work piece.

Therefore, proper care is taken while manufacturing the template as it is the heart of all other parts.

The template that we've with us is manufactured through the following stages:

The EN8 carbon steel raw material is first face and end milled to the required dimension. 
Drilling of holes on the template using conventional drill. Counterboring on the template for fastening purpose. Chamfering the drilled holes.

\section{The finished template is as shown below:}

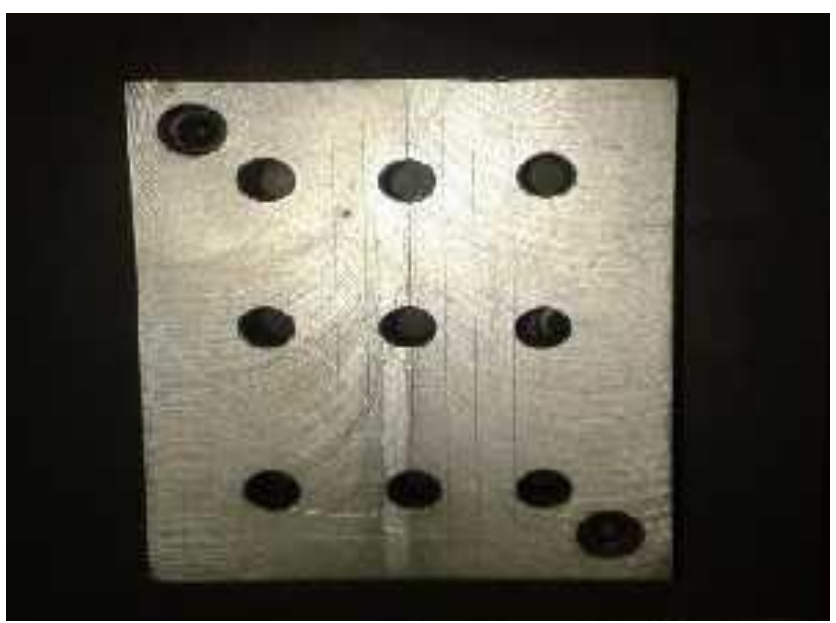

Fig 1.14: Template

\section{CONCLUSION}

From this project the following conclusions can be drawn:

1. Complete elimination of jigs.

2. This project if employed saves a lot of money in the form of machine hour rate.

3. The design and manufacturing the parts involved in the REPLICATING POSITIONER are very simple and less time consuming as compared to other positioning techniques.

4. Quality costs are reduced considerably when compared to conventional machining.

5. The whole setup can be easily ported from one place to another without the requirement of earth movers.

6. If the template is made according to the required dimension accurately, then all the subsequent replicated parts can be manufactured with the same accuracy.

7. The overall cost of the setup is as less as ten thousand which is $1 / 100^{\text {th }}$ the cost of other SPMs and CNCs.

\section{SCOPE FOR FUTURE WORK}

1. With the use of servo motors, the whole system can be automated.

2. The coordinate movements of the slide/guide can be hydraulically actuated.

3. The locking of the slides can be made by using a right hand - left hand combinational lock nut which simultaneously arrests the coordinate movement of the slide.

4. The antifriction balls used in the frictionless movement of the slides can be replaced by rollers.

\section{REFERENCES}

[1] Dewald, W. G., Thursby, J. G., and Anderson, R. G. 1988. Replication in empirical economics:

[2] The Journal of Money, Credit, and Banking project: The American Economic Review

[3] Lovell, M. C., and D. D. Selover. 1994. Econometric software accidents.

[4] Economic Journal Maddala, G. S. 1992. Introduction to econometrics MacMillan Publishers.

[5] McCullough, B. D., and H. D. Vinod. 1999. The numerical reliability of econo-metric software.

[6] D. B. Miracle and S. L. Donaldson, Introduction to Composites, ASM Handbook, Vol 21, 2001.

[7] T. Prater, Friction Stir Welding of Metal Matrix Composites for use in aerospace structures, Acta Astronautics, Vol 93, 2014, pp 366-373.

[8] S. Sarangi and D. Kumar, Fabrication and Characterization of Aluminium-Fly Ash Composite Using Stir Casting Method, B.Tech. Thesis, National Institute of Technology, Rourkela, 2009.

[9] X. Huang, Fabrication and properties of Carbon fibers, Materials, Vol 2, 2009, pp 2369-2403 